الاضطرابات السلوكية لاى لاعبين ذوي الاعاقة البدنية للألعاب الفردية لفئة الثباب

زينب صبري حازم (1)، سناء مجيا محمد (20)

تأريخ تقديم البحث: (2020/5/31)، تأريخ قبول النشر (2020/7/16).

DOI: https://doi.org/10.37359/JOPE.V32(3)2020.1016

المستخلص

هدف البحث الى معرفة الاضطرابات السلوكية والتي قد توجد لدى فئة ذوي الإعاقة (انواع الثنلل والبتر كلها) من الممارسين للفعاليات الرياضية الفردية ومدى تأثنرها في طبيعة الحياة لهم في اظهار هكذا سلوكيات التي بدورها تعكس حالتهم النفسية، ولأجل تحقيق هدف الدراسـة اتبع الباحثان المنهج الوصفي بالأسلوب المسحي، من خلال بناء مقياس خاص بالاضطرابات السلوكية لذوي الإعاقة والتي اتبع فيها الباحثان كافة الثروط العلمية في بناءها وتم تطبيقها على عينـة مـن مجتمـع البحث تمثلت بـ (100) لاعب ولاعبـة. وبلـغ متوسط الحسـابي لاعمارهم

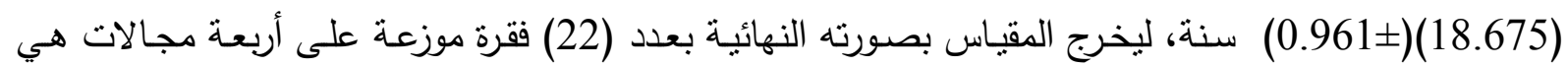

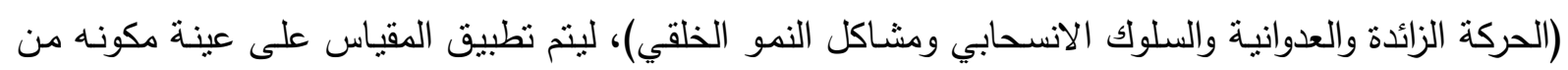
(80) لاعب ولاعبـة بمتوسط حسابي للعمر بلـغ (18.96)(土 خرج الباحثان بأن غالبية افراد العينة يتمتعون باضطرابات سلوكية متوسطة، كما ان المنافسة الرياضية والاعاقة هي أحد الأسباب الرئيسية في ظهور منل هكذا اضطرابات. الكلمات المفتاحية: الحركة الزائدة، مشاكل النمو الخلقي، السلوك الانسحابي، العدوانية.

\title{
ABSTRACT \\ Behavioral Disorders in Physically Challenged Individual Sports Youth Athletes
}

The researchers aimed at identifying the effect of behavioral disorders in physically challenged individual sports athletes and the level of its effect on their life. The researchers used the descriptive method on (80) physically challenged individual sport athletes. The researchers designed a scale for behavioral disorders for physically challenged that consisted of four fields. The data was collected and treated to conclude that most athletes have mild behavioral disorders. In addition to that, the researchers concluded that athletic competitions and disability are major reasons for these disorders.

Keywords: hyper Active, growth problems, withdrawal, aggression.

(1) طالبة دراسات عليا (الماجستير)، جامعة بغداد، كلية التربية البننية وعلوم الرياضة. (Zalazawi7@gmail.com) Zaineb Sabri Hazem, Post Graduate Student (Master), University of Baghdad, College of Physical Education and Sport Sciences, (zalazawi7@gmail.com) (+9647730385238).

(2) أستاذ، دكتوراه تربية رياضية، جامعة بغداد، كلبة التربية البننية وعلوم الرياضة (sanaa_altamimy@yahoo.com) Sanaa Majeed Mohammed, Prof (PH.D), University of Baghdad, College of Physical Education and Sport Sciences, (sanaa_altamimy@yahoo.com) (+9647702276317). 
ان ظاهرة الاضطرابات السلوكية بين الافراد وخاصة من ذوي الاعاقة في المجتمعات بصورة عامة تحتل مكانة بارزة في الآونة الاخيرة من قبل الباحثين في مجال علم النفس الرياضي نظراً لتضمنها على جانب كبير من الاهمية في مدلولاتها وتأثيراتها، اذ ان تأثثرها يكون هام جداً وخاصة لذوي الإعاقة خلال مسيرتهم الرياضية من حيث نتائجهم في السباق.

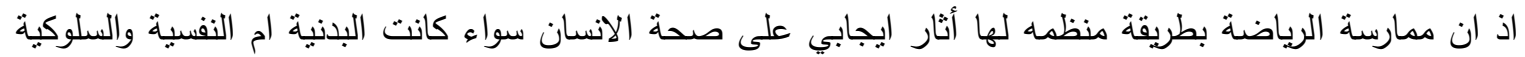
وتسهم الرياضة في تقليل وتخفيف من حده المعاناة النفسية السلوكية لدى ذوي الاعاقة. اذ يعد الاضطراب السلوكي بمفهومه "أنه استجابة الفرد للبيئة المحيطة بشكل غير مقبول اجتماعياً أو غير منوقع وله مقاومة للتعلم السوي ويتكرر بشكل غير مقبول. (kuffman .J.M, 1977, p. 30)، اذ يرجع الأسباب ظهور هذه الاضطرابات الى عدم الكفاية في القدرات العقلية والجسدية والجوانب الصحية للفرد ، والتي بدورها ستعمل على اظهار السلوكيات والمشاعر الغير ناضجة والغير ملائمة ضمن الظروف والاحوال العادية (139-Bower, 1978, pp. 131). وقد تتاولت العديد من الدراسات موضوع الاضطرابات السلوكية، اذ بينت دراسة (Achenbach, 1991) ان هناك

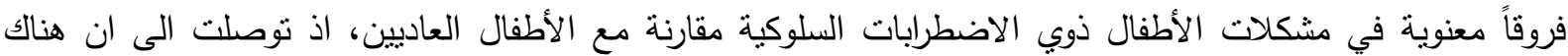

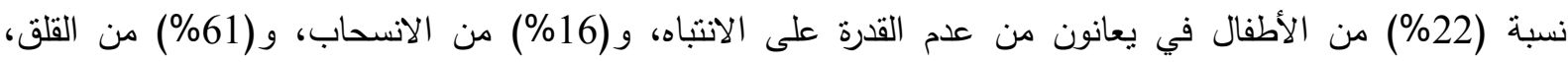
و (14\%) من المشكلات الاجتماعية، و (16\%) من الانحراف السلوكي و (15\%) من العدوانية، و (8\%) من المشكلات

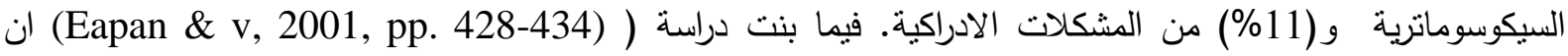
الاضطرابات السلوكية لدى الأطفال والمراهقين توجد وتظهر لهم مع بعض المشاكل الاسرية ونترافق ايضاً مع الصعوبات

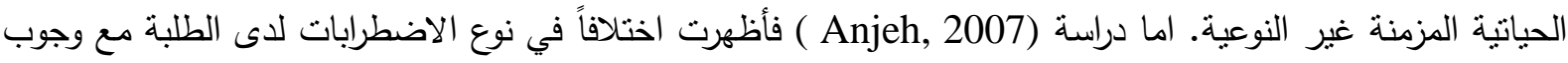
استعمال طرائق وأساليب لمعالجة كل اضطراب ومن هذه الاضطرابات (السلوكية والعاطفية والاعاقات الجسدية). اما دراسة (M.A. )

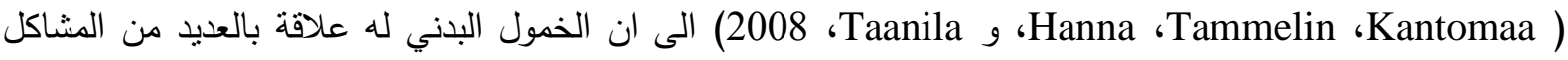
العاطفية والسلوكية لدى المراهقين، فيما جاءت دراسة (Lufi \& Parish, 2011, pp. 217-230) بان البرنامج العلاجي

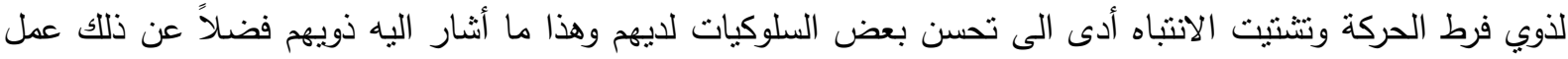

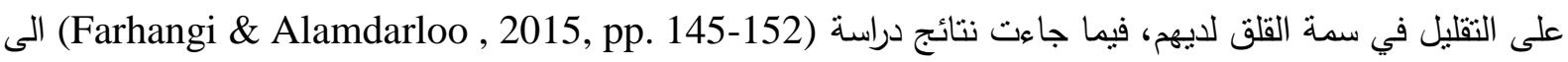

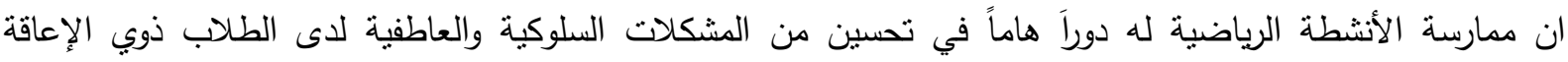

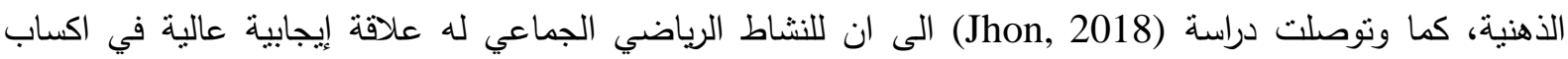
الثباب الصحة النفسية. ومن هنا تكمن أهمية الدراسة من خلال سعي الباحثان في معرفة الاضطرابات السلوكية والتي قد توجد لدى فئة ذوبي

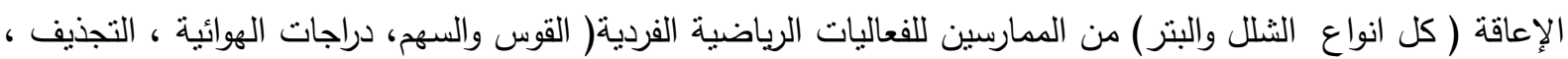
كرة الطاولة ، مبارزة ، التتس ، رفع الاثقال ، رماية ، سباحة ، التتس الطاولة، العاب القوى ) ، ومدى تأثنرها في طبيعة

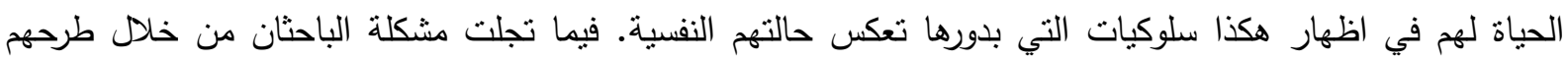

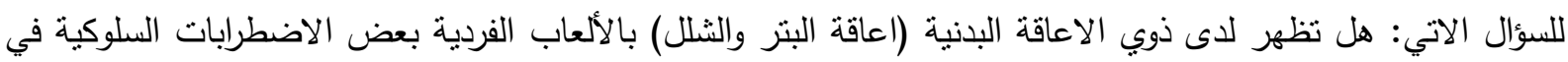
داخل بيئتهم الرياضية ام لا؟ وهل للإعاقة علاقة في ظهور بعض السلوكيات لذوب الاعاقة البدنية (اعاقة البتر وشلل) بالألعاب الفردية؟. اذ هدفت الدراسة في التعرف على واقع الاضطرابات السلوكية لدى اللاعبين الثباب لذوبي الاعاقة البدنية (اعاقة البتز والثلل) للألعاب الفردية. 
اعتمد الباحثان المنهج الوصفي بالأسلوب المسحي كون الأقرب لحل مشكلة البحث، وبعد تحديد مجتمع البحث والبالغ عدده (216) لاعباً يمثلون لاعبين ذوبي الإعاقة البدنية في جميع الألعاب الفردية وكانت نسبة الاعاقة للاعبين الثلل (89 ) لاعباً اما للاعبين البتر (127) لاعباً ، وبعد قام الباحث في تحديد عينة البحث البالغة عددها (190) لاعباً (عينة الاستطلاعية وبلغ عددهم (10) لاعبين، وعينة بناء المقياس والبالغ عددهم (100) لاعباً، اما عينة التقنين فبلغ عددهم (80) لاعباً. وان تحقيق هدف الدراسة لا يتم الا من خلال وجود مقياس خاص بالاضطرابات السلوكية لأجل التعرف على طبيعة هذه الاضطرابات لدى عينة البحث وبعد البحث والتقصى من قبل الباحثان تبين عدم وجود أداة محلية تتناسب مع اهداف البحث وطبيعة العينة، فمن دواعي هذا الاجراء في بناء المقياس هي الخصوصية بالنسبة لموضوع الدراسة، لذا فقد اعتمد الباحثان على نظرية (J.M, 1977, pp. 23-25) (Kaufman 1977) لأجل الاعتماد عليها لغرض وضع مجالات وفقرات التي تخص المقياس وصياغتها بواقعية وما تذهب اليه من تفسير سلوك كل ظاهرة من الظواهر المراد قياسها. اذ قام الباحثان في الاعتماد على الابعاد التي تشكل ظاهرة الاضطرابات السلوكية التي فسرتها نظرية (Kaufman 1977) والني تمنلت بـ (الحركة الزائدة والعدوانية والسلوك الانسحابي ومشاكل النمو الخلقي) والتي بدورها قام الباحثان بعرضهما على مجموعة من الخبراء والمختصين في علم النفس الرياضي لأجل معرفة صلاحيتهما والتي بدورها حصلت على اتفاق تام حول صلاحيتها، ليقوم الباحثان بوضع (22) فقرة تمثل المجالات الأربع وعرضها على مجموعة من ذوي الخبرة والاختصاص في علم النفس الرياضي لأجل بيان صلاحيتها وقد حصل الباحثان على اتفاق تام حول صلاحية الفقرات مع اجراء بعض التعديلات على (4) فقرات دون حدوث تغير في المعنى العام من الفقرة، فيما اعتمد الباحثان بدائل الإجابة على وفق مقياس ليكرن وعلى خمسة بدائل تمنلت بـ (موافق جداً، موافق، محايد، غير موافق،

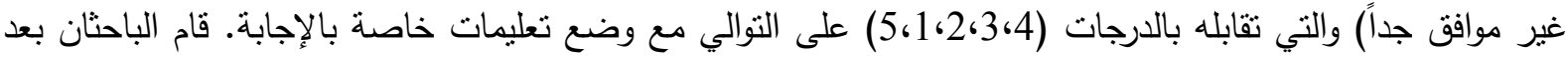

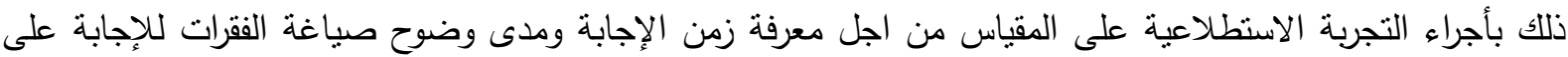
المقياس، ليتم بعدها اجراء تطبيق المقياس على عينة البناء البالغ عددها (100) لاعب ولاعبة وبعد استكمال الإجابات قام الإهاء الباحثان بأجراء التوصيف الاحصائي للمقياس من خلال الاعتماد على الأسس العلمية لذلك من صدق وثثات لأجل بيان مدى صلاحية المقياس، والتي تمثلت بـ: القدرة التميزية للمقياس

الجدول (1) يبين القدرة التميزية بين الحدود العليا والدنبا لعينة البحث

\begin{tabular}{|c|c|c|c|c|c|c|c|c|c|c|c|}
\hline \multirow{2}{*}{ الخطأ } & \multicolumn{2}{|c|}{ الحدود الدنيا 27\% } & \multicolumn{2}{|c|}{ الحدود العليا 27 \% } & \multirow{2}{*}{ ت } & \multirow{2}{*}{ الخطأ } & \multicolumn{2}{|c|}{ الحدود الدنيا 27\% } & \multicolumn{2}{|c|}{ الحدود العليا 27\% } & \multirow{2}{*}{ ت } \\
\hline & $\varepsilon^{ \pm}$ & سَ & $\varepsilon^{ \pm}$ & سَ سَ & & & $\varepsilon^{ \pm}$ & سَّ & $\varepsilon^{ \pm}$ & سَ & \\
\hline 0.041 & 1.251 & 3.018 & 1.012 & 4.111 & 12 & 0.048 & 0.854 & 3.963 & 0.891 & 4.444 & 1 \\
\hline 0.049 & 1.240 & 3.666 & 0.902 & 4.259 & 13 & 0.006 & 1.224 & 3.037 & 1.035 & 3.925 & 2 \\
\hline 0.000 & 0.751 & 1.777 & 1.187 & 3.444 & 14 & 0.000 & 1.074 & 3 & 0.769 & 4.148 & 3 \\
\hline 0.000 & 0.807 & 1.963 & 1.188 & 3.481 & 15 & 0.000 & 0.997 & 2.074 & 1.250 & 3.555 & 4 \\
\hline 0.000 & 1.120 & 2.111 & 1.217 & 3.592 & 16 & 0.000 & 1.275 & 2.629 & 1.135 & 3.851 & 5 \\
\hline 0.000 & 1.292 & 2.148 & 1.300 & 4 & 17 & 0.000 & 0.962 & 1.814 & 1.009 & 3.407 & 6 \\
\hline 0.003 & 0.878 & 4.185 & 1.591 & 3.074 & 18 & 0.000 & 1.067 & 2.296 & 1.120 & 3.555 & 7 \\
\hline 0.034 & 0.620 & 4 & 0.629 & 4.370 & 19 & 0.000 & 1.174 & 1.925 & 1.275 & 3.370 & 8 \\
\hline 0.001 & 0.735 & 3.263 & 0.577 & $\begin{array}{l}4.444 \\
\end{array}$ & 20 & $\begin{array}{l}0.000 \\
\end{array}$ & 1.174 & 1.925 & 1.241 & 3.185 & $\overline{9}$ \\
\hline 0.031 & 0.828 & 2.965 & 1.022 & 4.259 & 21 & 0.000 & 0.974 & 1.888 & 1.071 & 3.925 & 10 \\
\hline 0.028 & 0.916 & 3.074 & 1.012 & 4.111 & 22 & 0.000 & 0.944 & 2.259 & 1.018 & 3.963 & 11 \\
\hline
\end{tabular}

الاتساق الداخلي للفقرات: والذي تضمن إيجاد علاقة الارتباط بكل من (درجة الفقرة مع كل من الدرجة الكلية للمجال والمقياس، وعلاقة مع الدرجة الكلية للمجال مع الدرجة الكلية للمقياس. 


\section{مجلة التربية الرياضية - المجلى (32) - العدد (3) - سنة 2020.}

الجدول (2) يبين الاتساق الداخلي لمقياس الاضطرابات السلوكية لأفراد عينة البناء

\begin{tabular}{|c|c|c|c|c|c|c|c|c|}
\hline مستوى & قيمة R & ارتباط المجال بالدرجة & مستوى & بارتباط الفقرة & $ت$ & قيمة sig & بالمجاط الفقرة & ت \\
\hline \multirow{2}{*}{0.000} & \multirow{2}{*}{0.647} & \multirow{2}{*}{ الحركة الزائدة } & 0.000 & 0.380 & 1 & 0.000 & 0.432 & 1 \\
\hline & & & 0.009 & 0.260 & 2 & 0.000 & 0.532 & 2 \\
\hline \multirow{2}{*}{0.000} & \multirow{2}{*}{0.757} & \multirow{2}{*}{ العدوانية } & 0.000 & 0.420 & 3 & 0.000 & 0.587 & $\overline{3}$ \\
\hline & & & 0.000 & 0.536 & 4 & 0.000 & 0.549 & 4 \\
\hline \multirow{2}{*}{0.000} & \multirow{2}{*}{0.795} & \multirow{2}{*}{ السلوك الانسحابي } & 0.000 & 0.539 & 5 & 0.000 & 0.616 & 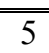 \\
\hline & & & 0.000 & 0.458 & 6 & 0.000 & 0.652 & 6 \\
\hline \multirow{2}{*}{0.026} & \multirow{2}{*}{0.423} & \multirow{2}{*}{ مشاكل النمو الخلقي } & 0.000 & 0.499 & 7 & 0.000 & 0.759 & 7 \\
\hline & & & 0.000 & 0.444 & 8 & 0.000 & 0.674 & 8 \\
\hline & & & 0.000 & 0.644 & 9 & 0.000 & 0.711 & 9 \\
\hline & & & 0.000 & 0.641 & 10 & 0.000 & 0.557 & 10 \\
\hline & & & 0.007 & 0.267 & 11 & 0.001 & 0.319 & 11 \\
\hline & & & 0.002 & 0.309 & 12 & 0.004 & 0.282 & 12 \\
\hline & & & 0.010 & 0.258 & 13 & 0.000 & 0.336 & $\overline{13}$ \\
\hline & & & 0.000 & 0.480 & $\overline{14}$ & 0.000 & 0.642 & $\overline{14}$ \\
\hline & & & 0.000 & 0.590 & 15 & 0.000 & 0.703 & $\overline{15}$ \\
\hline & & & 0.000 & 0.489 & 16 & 0.000 & 0.723 & 16 \\
\hline & & & 0.000 & 0.561 & 17 & 0.000 & 0.694 & 17 \\
\hline & & & 0.000 & 0.431 & 18 & 0.000 & 0.625 & 18 \\
\hline & & & 0.006 & 0.274 & 19 & 0.000 & 0.465 & 19 \\
\hline & & & 0.000 & 0.421 & 20 & 0.000 & 0.653 & 20 \\
\hline & & & 0.001 & 0.358 & 21 & 0.000 & 0.621 & $\overline{21}$ \\
\hline & & & 0.000 & 0.513 & 22 & 0.000 & 0.795 & 22 \\
\hline
\end{tabular}

يبين الجدولين (1) و (2) ان جميع الفقرات الخاصة بمقياس الاضطرابات السلوكية قد تمتعت بصدق بنائي عالٍ إضافة الى صدق المحتوى من خلال ما تم عرضة على الخبراء وحصلت على موافقة تامة له.

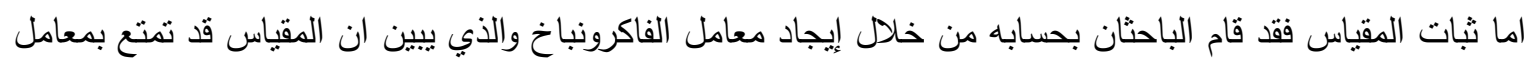

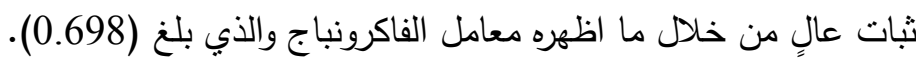
ثم قام الباحثان بتطبيق المقياس على عينة التطبيق بعد التأكد من صلاحية المقياس واستنفاءه للشروط العلمية الخاصة بيناء المقاييس على عينة تكونت من 80 لاعب ولاعبة لتبين بعد ذلك تقوم الباحثة في معرفة واقع

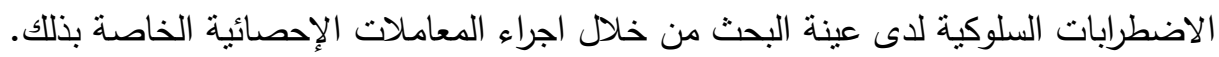

الجدول (3) التوصيف الاحصائي الوصفي لإجراءات تقنين مقياس الاضطرابات السلوكية

\begin{tabular}{|c|c|c|c|c|c|c|c|c|c|}
\hline قيمة ادىى & قيمة & التفلطح & معامل & للأوسأ المعباري & الانحراف & المنوال & الوسيط & الوسطي & ال التغير \\
\hline 47 & 92 & 0.839 & 0.767 & 0.997 & 8.924 & 69 & 65 & 66.150 & الاضطرابات السلوكية \\
\hline
\end{tabular}


الجدول (4) المعالم الإحصائية الخاصة بمقياس الاضطرابات السلوكية

\begin{tabular}{|c|c|c|c|c|c|c|c|}
\hline الدلالة & قالمحسوبة (ت) & الفرضي & الالمعراف & الوسط الحسابي & حجم العينة & المتغير & ت \\
\hline 0.881 & 0.150 & 66 & 8.924 & 66.150 & 80 & الاضطرابات السلوكية & 1 \\
\hline
\end{tabular}

" معنوي عند مستوى الخطأ (0.05) اذا كان مستوى الخطأ اصغر من (0.05).

واعتمد الباحثان في تحديد مستويات مقياس الدراسة على (5) مستويات، وعند توزيع الدرجات المعيارية على ملى (0.05)

المستويات المعتمدة ظهرت لنا المستويات المعيارية ( رشيد، 2017، صفحة 198) وكما مبين في الثكل (1)

الجدول (5) نوزيع المستويات المعيارية للضطرابات السلوكية

\begin{tabular}{|c|c|c|c|c|c|c|}
\hline قليلة & بسيطة & متوسطة & ش ش شيدة & ش شديدة جداً & المستويات المعيارية & الاضطرابات \\
\hline$\% 2,14$ & $\% 13,59$ & $\% 68,27$ & $\% 13,59$ & $\% 2,14$ & النسب المعيارية & السلوكية \\
\hline
\end{tabular}

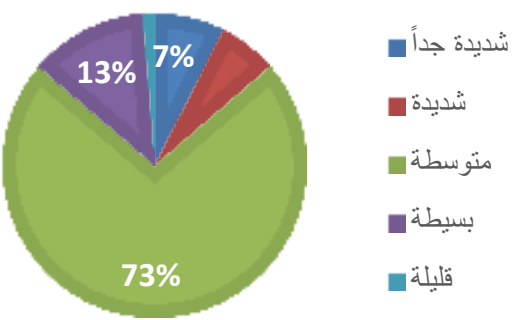

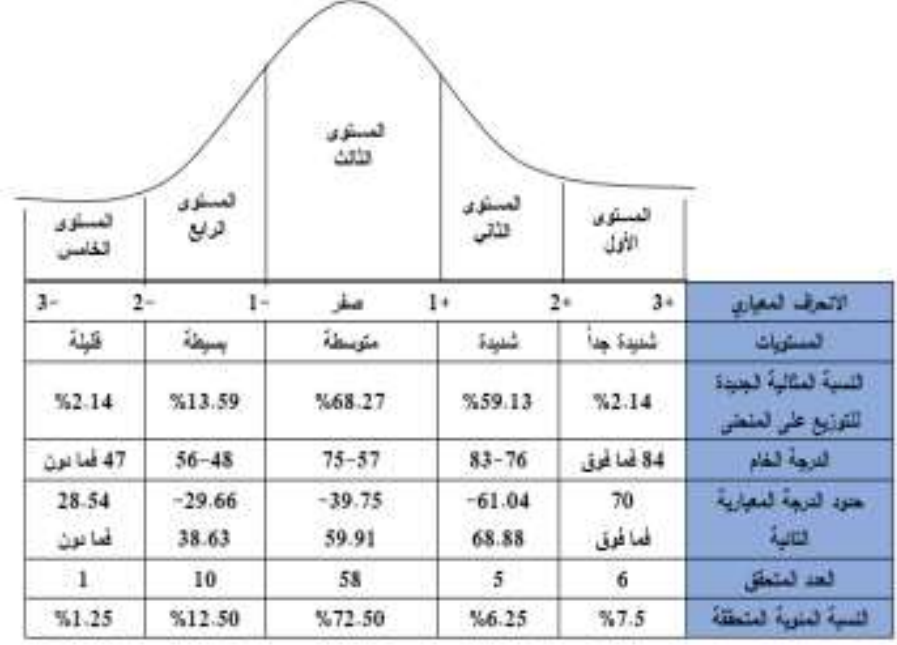

الثكل (1) النسبة المئوية المتحققة والعدد المتحقق لمقياس الاضطرابات السلوكية

يرى الباحثان من خلال الثكل (1) والتي أظهرت نتائج عينة البحث بان هناك نسب متفاوتة قياسا للنسب المثالية المقررة، ان هناك اضطرابات سلوكية لأفراد عينة البحث من خلال النسب الني اظهرتها الجداول الإحصائية اذ ان (7.5\%) من افراد العينة كان يتمتعون باضطرابات سلوكية عالية كونهم كانوا في المستوى الأول (شديدة جدا) وهي نسبة

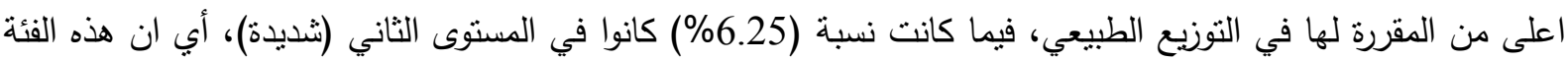

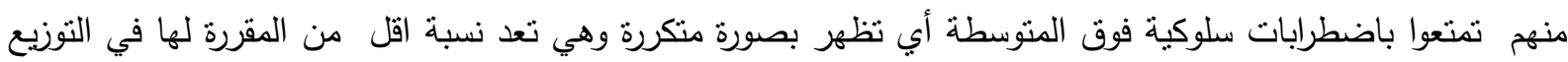
الطبيعي، فيما كانت فئة منهم قد نسبة مقدارها (72.50\%) اي في المستوى الثالث (متوسط) وهي نسبة اعلى من المقررة لها في التوزيع الطبيعي أي ان هذه الفئة يمتلكون اضطرابات سلوكية نظهر بصورة معتدلة أي بين الحين والأخر ، فيما حققت العينة نسبة مقدارها (12.50\%) في المستوى الرابع (بسيطة) أي ان امتلاكهم للاضطرابات هي بسيطة ونظهر

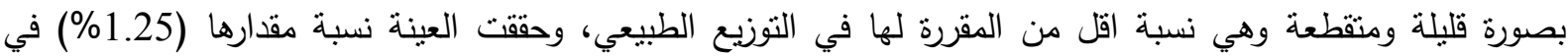
المستوى الخامس (قليلة) وهي نسبة اقل من المقررة لها في التوزيع الطبيعي. يرى الباحثان ان النسب التي ظهرت لدى عينة البحث هي نسب طبيعية ولكافة المستويات الخمس والتي ظهرت بأنها نسبة اكبر من النسب الطبيعية كون ان الاضطرابات السلوكية هي بالأساس موجوده وخاصة لاى هذه الفئة والني اشارت

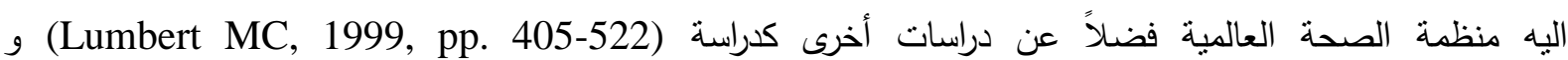


(koubekove, 2000, pp. 32-39) و (Oya, 2000, pp. 42-43)، كما ويفسر الباحثان ظاهرة الاضطرابات تعود الى عدة أسباب يوجزها الباحثان كالاتي:

هأسباب تعود الى عوامل جينية وبيولوجية: أي ان بطبيعة الانسان فأن سلوكه يتأثر بالعوامل الجينية والعصبية

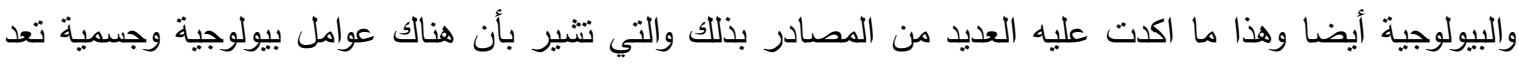
ذات صلة بالاضطرابات السلوكية والانفعالية ومنل الامراض المزمنة وسوء التغذية والعاهات والتشوهات الجسمية

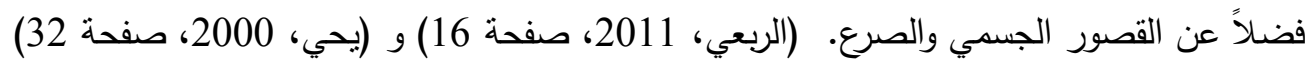
أسباب تعود الى جوانب نفسية: كون ان افراد العينة هم من اللاعبين ولديهم واجبات من الناحية الاجتماعية والرياضية

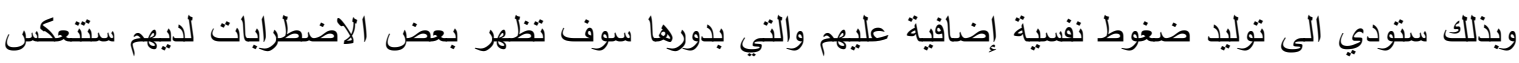

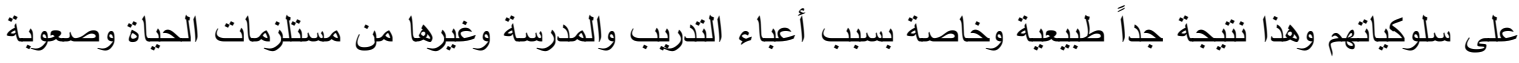

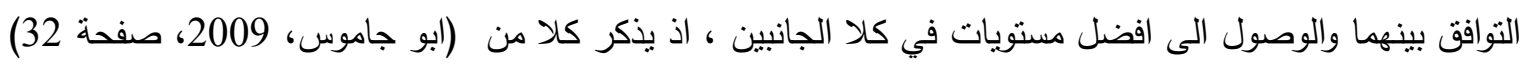

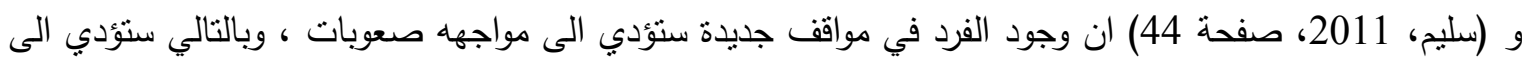
توليد ضغوط نفسية وتلك تعد من اهم الأسباب النفسية التي تلعب دوراً هاماً في تكوين وظهور الاضطرابات السلوكية دودية أسباب نعود الى وجود علل او خلل جسمي: ان افراد العينة وبالطبع يعانون من صراع نفسي كونهم غير اسوياء

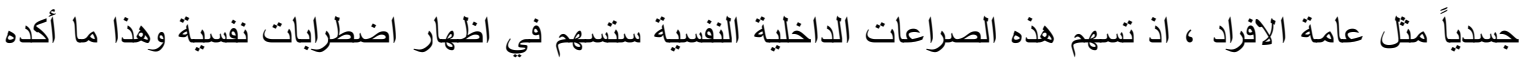
(بشناق، 2001، صفحة 82) ان الافراد الذي لديهخ عاه او مرض او نتوه خلقي يؤدي ذلك الى نشوء هيجان داخلي ورفض لحالتهم ومما يضع الفرد في جو نفسي مضطرب وبالتالي يؤدي ظهور متغيرات وسلوكيات مختلفة. أسباب تعود الى عدم القدرة والعجز: يشير (فايت، 2003، صفحة 22) و (بلعقون، 2019، الصفحات 34-35) ان

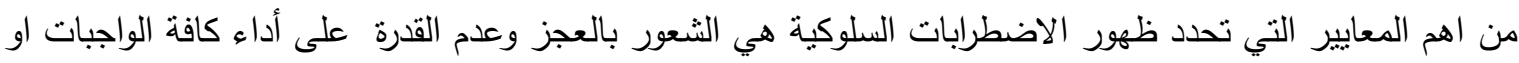

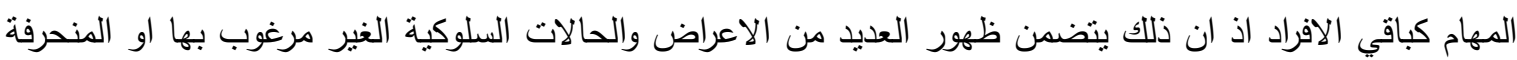

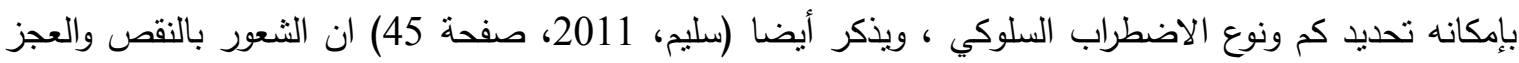

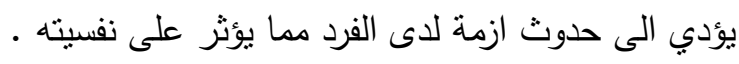

كما ويضيف الباحثان ان غالبية الرياضيين ذوي الإعاقة هم أصحاب إنجازات رياضية ومراكز متقدمة على العالم مما

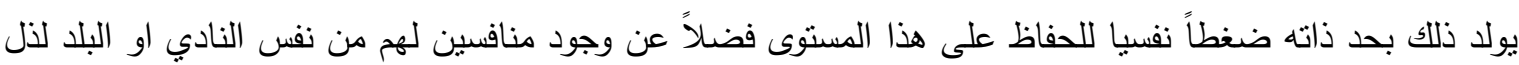
هذا بحد ذاته يثكل صراعاً نفسيا داخليا يؤدي الى هكذا سلوكيات. واستتتج الباحثان ان غالبية افراد العينة يتمتعون باضطرابات سلوكية متوسطة، كما ان المنافسة الرياضية والاعاقة هي أحد الأسباب الرئيسية في ظهور منل هكذا اضطرابات.

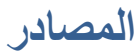

Achenbach, T. (1991). national survey of problems and competencies among four to sixteen years old child development.

Amaury Samalot - Rivera M.A. (2007) THE EFFECT OF SOCIAL SKILL INSTRUCTION ON SPORT AND GAME RELATED BEHAVIORS OF CHILDREN AND ADOLESCENTS WITH EMOTIONAL OR BEHAVIORAL DISORDERS.) College of Education and Human Ecology ،The Ohio State University.

Bower, F. (1978). Pathwayes upstream:risks and reatities of early screening effect. American Journal of the psychiatry,84. 
Divine Anjeh.) April, 2007). Dealing with Emotional, behavioral and physical disabilities(the teacher's challenge). Educating Learners with Diverse needs.

Eapan ، v. .(2001) Childhood Behavioral disturbance in community simple in AL-ain. .7 3 United Aarab Emarates Easterm Meditteraneneam Health Journal.

Fatemeh Farhangi ،Ghorban Hemati Alamdarloo . .(2015) Effect of Sports Activities on Behavioral-Emotional Problems of Students with Intellectual Disability. .(5)3 specific physical therapy journal.

J.M, K. (1977). Characteristics of children behaviors disorders . columbus .Ohaio .

Jhon, G. (2018). The Effect of Team Sports On Mental Health In Adolescents. In S. S. Kinesiology (Ed.). State University of New York.

koubekove, E. (2000). Personal and social adjustment of physically handicapped pubescent psychologia Dietata.

kuffman .J.M. .(1977) Characteristics of children behaviors disorders, Columbus. Ohaio.

Lufi, D., \& Parish, J. (2011). Sport-Based Group Therapy Program for Boys with ADHD or with Other Behavioral Disorders. Child \& Family Behavior Therapy.

Lumbert MC, e. .. (1999). Behavior and emotional problems of clinic Referred Children in school of African and Jamaican children age (4-18). 4, 29. Journal of black psychologe.

Marko T Kantomaa ،Tuija H Tammelin ‘E Ebeling Hanna g ‘Anja M Taanila. .(2008) Emotional and Behavioral Problems in Relation to Physical Activity in Youth. university of Oulu ,finland.

Oya, M. .. (2000). iolence exposure and behavioral problems among children and adolescent in clinical population Dissertation Abstract Internationa. 8.

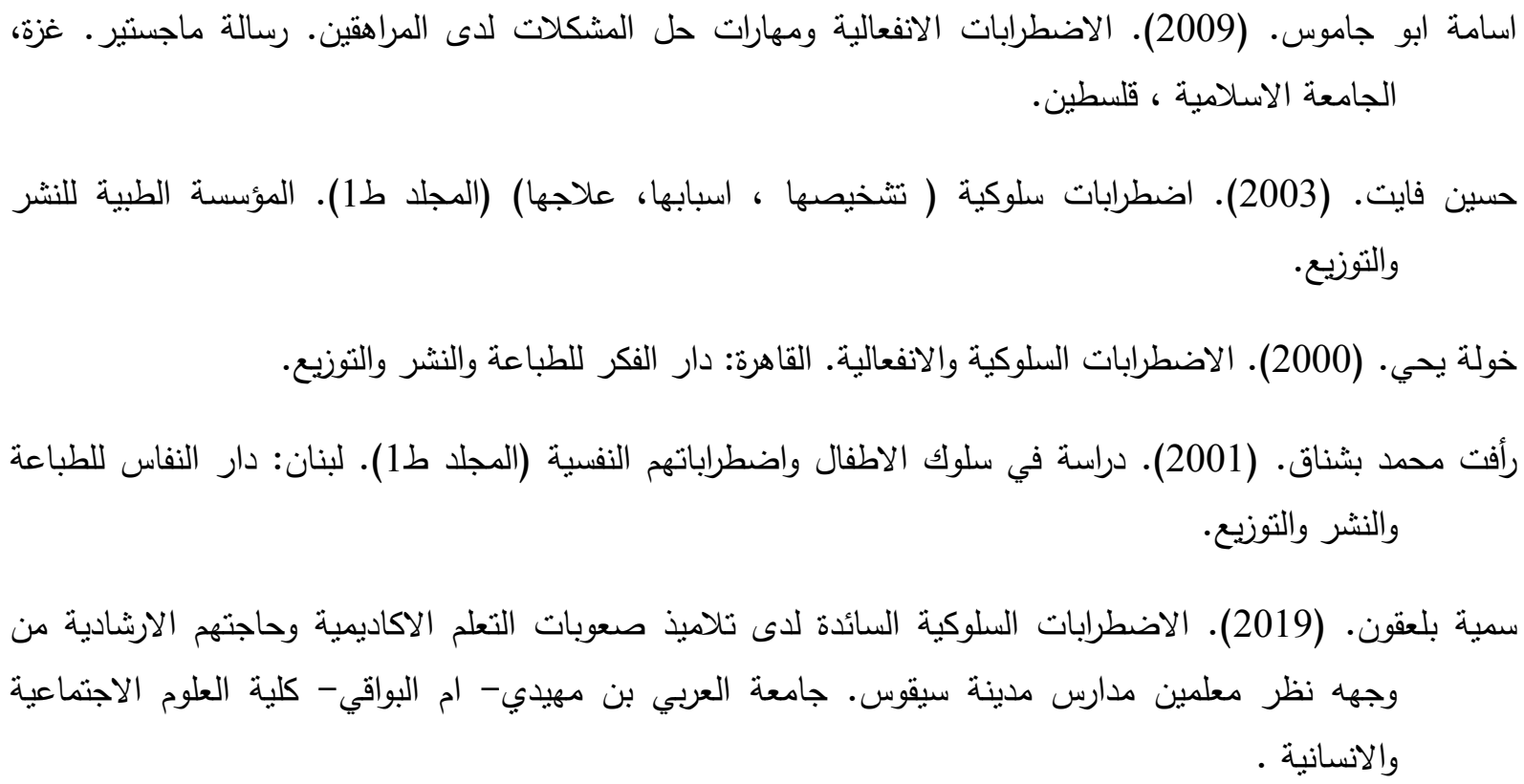




\section{مجلة التربية الرياضية - المجلد (32) - العدد (3) - سنة 2020.}

عبد الرحمن ناصر رشيد. (2017). مدخل الى الإحصاء التطبيقي في علوم التربية الرياضية (المجلد ط1). عمان، الاردن: دار الوضاح للنشر.

عبد العزيز ابراهيم سليم. (2011). المشكلات النفسية والسلوكية لدى الاطفال (المجلد ط1). عمان، الاردن: دار المسيرة للنشر والتوزيع والطباعة.

علاء جمال الربعي. (2011). الاضطرابات السلوكية والانفعالية لدى الاطفال الصم وعلاقتها بالتوافق الاسري. رسالة ماجستير • الجامعة الاسلامية -غزة /كلية التربية /قسم علم النفس.

الملاحق

الملحق (1) مقياس الاضطرابات السلوكية

\begin{tabular}{|c|c|c|c|c|c|c|}
\hline $\begin{array}{l}\bar{F} \\
\bar{b}: \\
\frac{b}{G} \\
\bar{F} .\end{array}$ & 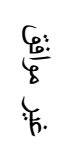 & : & $\frac{6:}{g}$ & $\begin{array}{l}\bar{F} \\
6: \\
\bar{g}\end{array}$ & 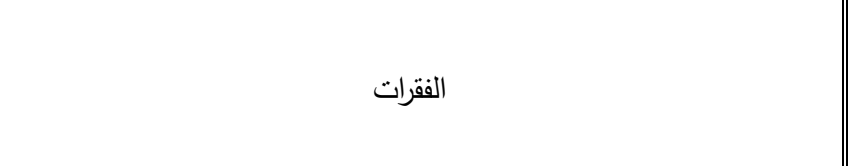 & $ت$ \\
\hline & & & & & لدي عزيمة تكفيني في مواجهة العقبات التي تظهر اثناء التدريب & 1 \\
\hline & & & & & لدي شعور ان اندفاعي هي سبب اخطائي في المسابقة & 2 \\
\hline & & & & & أحتاج الى جهر للانتباه الى تعليمات الددرب & 3 \\
\hline & & & & & ليس لدي قدره على النركيز & 4 \\
\hline & & & & & أجد صعوبة في السبطرة على انفعالاتي اثثاء التنريب & 5 \\
\hline & & & & & لدي القدرة على خلق شجار مع أصدقائي & 6 \\
\hline & & & & & أفضل مشاهدة الالعاب القتالية عن غيرها من الالعاب. & 7 \\
\hline & & & & & افكر بإيقاع الضرر بالأخرين & 8 \\
\hline & & & & & أرد الإساءة البذنية بأقوى منها & 9 \\
\hline & & & & & أصرخ لأسباب تافهة & 10 \\
\hline & & & & & يراودني الاحباط والتوتر كلما فكرت بالصعوبات التي تواجهني اثناء التنريب. & 11 \\
\hline & & & & & الفثل بالنسبة لي هو مجرد محاولة لم تنتهي & 12 \\
\hline & & & & & لا تهمني نظرة المجتمع تجاهي & 13 \\
\hline & & & & & اشعر بالخوف من ترك الناس لي بسبب اعاقتي & 14 \\
\hline & & & & & اهرب عندما تواجهني مشاكل & 15 \\
\hline & & & & & ما مررت به جعلني انطوائي & 16 \\
\hline & & & & & اهرب من مشاكلي بأحلام اليقظة & 17 \\
\hline & & & & & اشعر بأنني غريب عن الفريق الذي انتمي اليه & 18 \\
\hline & & & & & ساعدنتي التمارين الرياضية في استعادة ثقتي بقواي البدنية & 19 \\
\hline & & & & & أمتلك مشاعر نساعدني على التوجه للمستقبل نحو الافضل & 20 \\
\hline & & & & & امتلاك افكار تساعدني على تخطي اعاقتي & 21 \\
\hline & & & & & للدي القدرة على ضبط افعالي خلال عملية التدريب والمنافسة & 22 \\
\hline
\end{tabular}

